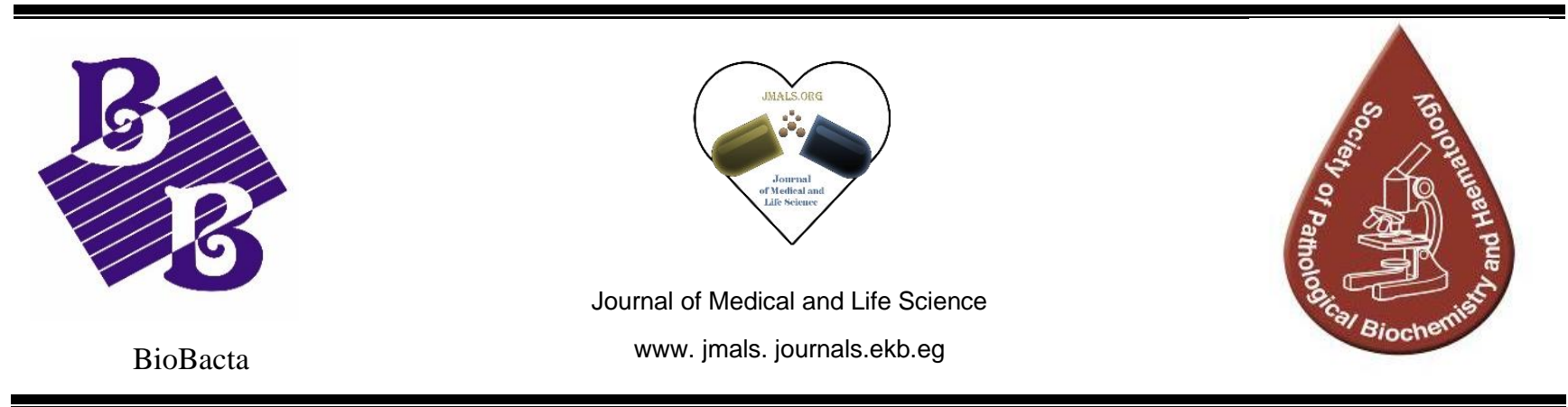

\title{
Anti-proliferative effect of ZnO NPs against the growth of Ehrlich Solid carcinoma
}

\section{${ }^{1}$ Lamees Dawood, ${ }^{* 2}$ Ehab Tousson, ${ }^{2}$ Afaf El-Atrsh, ${ }^{2}$ Amira Salama}

\author{
${ }^{1}$ Medical Biochemistry, Faculty of Medicine, Tanta University, Tanta, Egypt \\ ${ }^{2}$ Department of Zoology, Faculty of Science, Tanta University, Tanta 31527, Egypt \\ *Corresponding author: ehabtousson@science.tanta.edu.eg \\ ORCID ID: 0000-0001-9722-3603 \\ DOI: 10.21608/jmals.2019.180380
}

\begin{abstract}
Background: Zinc oxide nanoparticle ( $\mathrm{ZnO}$ NPs) has been widely used in biomedical applications and cancer therapy and has been reported to induce a selective cytotoxic effect on cancer cell proliferation. Methods: Female Swiss Albino mice were inoculated subcutaneously with Ehrlich ascites carcinoma (EAC) cells. ZnO NPs or MTX were injected intraperitoneally. Tumor growth inhibition rate (TIR \%), increase in life span (ILS\%), zinc concentration, lipid peroxidation marker (MDA), glutathione (GSH) contents, and the activity of the antioxidant scavenger enzymes SOD and catalase CAT was examined. Also, DNA fragmentation and histopathological studies of all groups were carried out. Results: Treatment of tumor-bearing mice with $\mathrm{ZnO}$ NPs significantly increased (MST), (TIR \%), (ILS \%) and reduced tumor weight, compared to tumor-bearing controls. Additionally, Zn concentration and DNA fragmentation were significantly increased in tumor tissues. $\mathrm{ZnO}$ nanoparticles were also found to induce oxidative stress, evidenced by the generation of reactive oxygen species and depletion of the antioxidants in tumor tissues, with no changes in the liver. Our data demonstrate that $\mathrm{ZnO}$ NPs exert distinct effects via the killing of cancer cells. Conclusion: The study findings demonstrated that the ZnO NPs can induce selective cytotoxicity through reactive oxygen species generation and oxidative stress.
\end{abstract}

Keywords: Zinc oxide nanoparticles, Methotrexate, Ehrlich solid tumor, selective cytotoxicity, zinc concentration, oxidative stress, DNA fragmentation.

\section{Introduction}

Cancer is a condition of uncontrolled cell differentiation, which has been treated by several modalities, including chemotherapy, radiation, and surgery, during the past several decades. ${ }^{[1,2]}$ Current anticancer chemotherapies based on alkylating agents, antimetabolites, biological agents and natural products frequently fail to produce a complete anticancer response owing to the development of drug resistance or their failure to differentiate effectively between cancerous and normal cells. ${ }^{[3-7]}$ This indiscriminate action frequently leads to systemic toxicity and debilitating adverse effects in normal body tissues, including bone marrow function suppression, neurotoxicity, and cardiomyopathy, which greatly limits the maximal allowable dose of the chemotherapeutic drug. ${ }^{[8]}$ Nanoparticles have been known as a promising agent for cell imaging, biosensing, gene delivery, and cancer therapy. Metal oxide nanoparticles (NPs) such as zinc oxide nanoparticles ( $\mathrm{ZnO} \mathrm{NPs}$ ) have been used in biomedical applications and various therapy. ${ }^{[9]}$ The manipulation of $\mathrm{ZnO}$ at the nanoscale levels enables precision engineering to control the physicochemical properties of nanoparticles and their interactions with cellular systems. ${ }^{[10]} \mathrm{ZnO}$ has been widely used in 
cosmetic lotions and increases anti-bacterial activity. ${ }^{[11,12]}$ It is also utilized in the cotton fabric, rubber, and food packaging industry. ${ }^{[13]}$

Zinc oxide nanoparticles have attracted researchers for their implications in cancer therapy and have been reported to induce cytotoxicity at in vitro and in vivo Levels. ${ }^{[14]} \mathrm{ZnO}$ NPs have been found to have the potential for use in biomedical and cancer applications due to the attractive chemical properties of these nanomaterials. ${ }^{[15]}$ Previous studies reported that $\mathrm{ZnO}$ NPs exhibit a high degree of cancer cell selectivity with the ability to surpass the therapeutic indices, compared to chemotherapeutic agents. ${ }^{[16]}$ ZnO NPs able to preferentially target rapidly dividing cancerous cells, which could serve as a foundation for developing novel cancer therapeutics. ZnO NPs show enhanced cytotoxicity by a generation of reactive oxygen species (ROS), leading to oxidative stress and eventually cell death when the antioxidative capacity of the cell is exceeded. ${ }^{[15]}$ ROS are oxygen metabolites that are highly active in terms of oxidative modifications of cellular macromolecules including proteins, lipids, and polynucleotides. ${ }^{[17]}$ The cellular redox homeostasis is maintained by the balance between ROS production and the antioxidant system in the cell; when ROS is produced excessively or endogenous antioxidant capacity is diminished, indiscriminate oxidation elicits harmful effects, resulting in "oxidative stress". Several studies proved that excessive oxidative stress is harmful to the cell and causes severe cytotoxicity. ${ }^{[17-19]}$ Upon exposure to oxidants or oxidative stress-inducing agents, a common adaptive response induced in mammalian cells is the upregulation of stress-response genes, many of which encode antioxidant defense enzymes. ${ }^{[20-22]}$ While high levels of ROS production may lead to the induction of apoptosis or necrosis, increasing evidence demonstrates that low or transient ROS exposure increases cell proliferation, likely through altered expression of growth factors and proto-oncogenes. ${ }^{[23,24]}$ Experimental tumors have great importance for modeling, and one of the commonest is the Ehrlich solid tumor was chosen as the experimental model of carcinogenesis. ${ }^{[25]}$ It is a neoplasm of epithelial origin, corresponding to murine mammary adenocarcinoma. This tumor is easily cultivated and transferred in vivo and can be used to study the mechanisms of carcinogenesis and evaluate the effect of new therapeutic approaches for tumors. ${ }^{[25]}$ The present study was aimed to investigate the selective toxicity of $\mathrm{ZnO}$ NPs against Ehrlich solid carcinoma in mice.

\section{Materials and methods}

\subsection{Materials}

Zinc oxide nanoparticles ( $\mathrm{ZnO} \mathrm{NPs}$ ) with a diameter of 20-50 nm were purchased from SigmaAldrich Company Ltd. The purities of ZnO NPs was 99.5 wt. \%. The particular surface areas of ZnO NPs were $50 \mathrm{~m}^{2} / \mathrm{g}$. This physicochemical information was provided by the manufacturer. Methotrexate (MTX) was purchased from Sanofi (Cairo, Egypt). All different reagents and chemicals employed in this study were purchased from Bio- Diagnostic Medical Company (Egypt).

\subsection{Animals}

In total, 115 Albino, female mice individually weighing around $20-25 \mathrm{~g}$ were housed in wire mesh cages in a constant environment [temperature $\left(23^{\circ} \mathrm{C} \pm\right.$ $\left.2^{\circ} \mathrm{C}\right)$, relative humidity $(80 \% \pm 5 \%)$, and light $(12 \mathrm{~h}$ light/dark cycles)]. They were given ad lib access to a standard diet and water. All experiments were performed following guidelines for animal studies issued by the Ethical Committee of Faculty of Science and Faculty of Medicine, Tanta University, as approved by the Institutional Animal Care and Use Committee (IACUC-SCI-TU-0041).

\subsection{Ehrlich Ascites Carcinoma (EAC) Cells and Tumor Inoculation}

Murine Ehrlich Ascitis Carcinoma bearing mouse was obtained from National Cancer Institute, Cairo University (Giza, Egypt). Mice were implanted with $0.2 \mathrm{ml}$ of Ehrlich tumor cell suspension (containing about $2 \times 10^{6}$ viable cells) injected subcutaneously to the right hind limb of the mice for the experiment on day 0 .

\subsection{Animal treatments}

Mice were randomly divided into the following groups:

Control (healthy) group [control] injected intraperitoneally by $200 \mathrm{~mL}$ saline $(\mathrm{n}=15)$

$\mathrm{ZnO}$ NPs control group [ZN] contained normal mice injected intraperitoneally by $\mathrm{ZnO} \mathrm{NPs}(10 \mathrm{mg} / \mathrm{kg}$, once daily for 3 weeks) $(n=25)$

Ehrlich control group [E] included mice subcutaneously implanted by Ehrlich tumor cells $(n=25)$.

ZnO NPs -treated group $[\mathrm{E}+\mathrm{ZN}]$ contained mice injected intraperitoneally by $\mathrm{ZnO} \mathrm{NPs}(10 \mathrm{mg} / \mathrm{kg}$, once daily for 3 weeks $^{[26]}$ administered 7 days after subcutaneous implantation of Ehrlich tumor cells $(n=25)$.

MTX-treated group [E + MTX] contained mice injected intraperitoneally by MTX $(1.25 \mathrm{mg} / \mathrm{kg}$, every 48 hours for 2 weeks) administered 7 days after subcutaneous implantation of Ehrlich tumor cells $(n=25)$.

At the end of the experiment, animals were examined for body weight changes (BW): 
(initial BW on day 0, last and net final BWs). Net final $\mathrm{BW}=($ final $\mathrm{BW}-$ tumor weight $)$.

BW gain was determined as body weight gain (final BW- initial BW/ initial BW) x100.

\subsection{Sample preparation}

One month after tumor inoculation, 15 mice from each group were anesthetized by decapitation under ether anesthesia and sacrificed to (1) evaluate the anti-tumor activity of ZnO NPs and (2) conduct a biochemical and histopathological assay. Livers were immediately removed from mice ( $n=15 /$ group), weighed, and sliced into two parts. Ehrlich tumors were carefully removed from the right thigh. Solid tumors were excised for tumor weight determination, longest and shortest diameters of the tumor were measured with the help of a vernier caliper. Tumor volumes were calculated by the following: Tumor volume $(\mathrm{mm} 3)=\left(\right.$ length $\mathrm{x}$ width $\left.{ }^{2}\right) / 2$, where the length and width are given in $\mathrm{mm} .{ }^{[27]}$

Tumor tissues were then washed with ice-cold saline three times then chilled on ice. Tumors were divided into two sections, one was kept in $10 \%$ neutral buffer formalin for the histopathological examination, and the second was wrapped in aluminum foil, and stored at $-20^{\circ} \mathrm{C}$ till used for measuring zinc content and biochemical assay. ${ }^{[28]}$

\subsection{Calculation of MST and percentage of ILS, T/C, and TIR}

The remaining mice ( $\mathrm{n}=10$ mice/group) were kept a live to estimate the mean survival time (MST) and percent increase in life span (\% ILS). MST of each group was monitored by recording the mortality daily. The endpoint of the experiment was determined by the spontaneous death of animals and MST was calculated according to the equation: MST $=$ (day of first death + day of last death)/2. The percentage of ILS was calculated using an equation of (ILS\% $=(T$ $-\mathrm{C}) / \mathrm{C} \times 100$ ), where T represents MST of treated animals and $\mathrm{C}$ represents MST of [E] group. T/C\% (treated vs. ESC control [E]) was calculated as MST of treated animals/MST of [E] group. TIR\% (tumorgrowth inhibition rate $)=(\mathrm{C}-\mathrm{T}) / \mathrm{C} \times 100$, where $\mathrm{T}$ represents the mean tumor volume of the treated group and $\mathrm{C}$ represents the mean tumor volume of the ESC control [E] group. ${ }^{[29]}$ According to the criteria of the National Cancer Institute (NCI), T/C exceeding $125 \%$ and ILS exceeding $25 \%$ indicate that the drug has significant anti-tumor activity. ${ }^{[30]}$

\subsection{Measurement of zinc content in liver and ESC using ICP-OES}

Tumor/mammary glands and liver samples weighing $0.5 \mathrm{gm}$. were prepared for quantitative estimation of their zinc concentration using inductively coupled plasma optical emission spectrometry ICP-OES (Thermo Scientific iCAP 7000). $0.5 \mathrm{gm}$ of tumor tissue samples were digested in a microwave oven digestive system with $\mathrm{HNO}_{3}$ (65\%) and $\mathrm{H}_{2} \mathrm{O}_{2}$ (30\%) in Teflon vessels., The residues were filtered through $0.45 \mu \mathrm{mWhatman}$ filter paper and transferred to a $50 \mathrm{~mL}$ volumetric flask and diluted to $50 \mathrm{~mL}$ with deionized water then analyzed for zinc content (analytical wavelength chosen was $213.857 \mathrm{~nm}$ ). The amount of zinc was calculated from the linear portion of the generated standard curve. ${ }^{[31]}$

\subsection{DNA extraction and fragmentation analysis}

The genomic DNA was extracted from the mammary gland and tumor tissue samples using Gene JET genomic DNA extraction kit following the manufacturer's protocol (Fermentas, \#K0721, European Union). Followed by, agarose gel electrophoresis (2\%) to detect DNA fragmentation according to Abd Eldaim et al. ${ }^{[32]}$ The fragment patterns (ladder, smear, or intact) were visualized on the UV Trans-illuminator and photographed by a gel documentation system (UVDI Major Science, USA). All samples were processed at one time, to avoid variations due to the extraction method itself.

\subsection{Determining oxidative stress biomarkers}

Tumor/mammary gland and liver were soaked in PBS ( $\mathrm{pH} 7.4$ ) containing $0.16 \mathrm{mg} / \mathrm{ml}$ heparin to remove any red blood cells and clots, and then it was homogenized in $5 \mathrm{ml}$ cold buffer $(50 \mathrm{mM}$ potassium phosphate, $\mathrm{pH}$ 7.5). The homogenate was then centrifuged at 4,000 rpm for 15 minutes, and the supernatant was carefully collected. To determine the malondialdehyde (MDA) component, a noxious product of lipid peroxidation was detected according to the following: lipid peroxidation was evaluated based on MDA level, MDA was determined using the method as previously described by El Atrash et al. ${ }^{[33]}$ Assay of catalase enzyme activity (CAT; EC 1.11.1.6) was measured by monitoring the decomposition of $\mathrm{H}_{2} \mathrm{O}_{2}$ (the substrate of the enzyme) at $240 \mathrm{~nm}$ according to the method described by Salama et al. ${ }^{[34]}$ Assay of superoxide dismutase enzyme activity (SOD; EC 1.15.1.1) in liver homogenate was assayed by the method of Habig et al. ${ }^{[35]}$ Assay of reduced glutathione (GSH) content determination is based on the reduction of 5,5dithiobis (2-nitrobenzoic acid), and it was determined by the colorimetric method according to Barakat et al. ${ }^{[36]}$

\subsection{Statistical analysis}

The data are expressed as the mean \pm standard error of the mean (SEM). One-way analysis of variance (ANOVA) was used to assess significant differences among treated groups and control. The 
Tukey test was used to compare all groups with each other and showed the significant effect of treatment. The criterion for statistical significance was set at* means $\mathrm{p} \leq 0.05$, (Graph Pad Prism Software).

\section{Results}

\subsection{Animal observation and anti-tumor effects of ZnO-NPs against ESC}

To evaluate the anti-tumor effects of ZnO-NPs against ESC, changes in body weight, tumor volume, tumor-growth inhibition rate (TIR \%), mean survival time (MST), an increase in life span (ILS \%) of treated groups were observed [Table 1]. No toxic signs or mortality were observed related to ZnO-NPs administration in contrast to MTX. Moreover, administration of $\mathrm{ZnO}-\mathrm{NPs}$ led to a significant decrease $(p<0.001)$ in tumor volume and weight in comparison with ESC mice. On the other hand, treatment of mice ( $n=10$ /group) with $\mathrm{ZnO}-\mathrm{NPs}$ or MTX significantly increased ILS\% with a rate of $111.66 \%(\mathrm{P}<0.001)$ and $55.3 \%(\mathrm{P}<0.01)$, respectively, as compared to non-treated ESC mice. Similar treatments led to a notable increase in MST with $75.5(\mathrm{P}<0.001)$, and $55.6(\mathrm{P}<0.01)$ days, respectively, as compared to non-treated ESC mice (35 days). The Tumor-growth inhibition rate (TIR \%) of the Ehrlich tumor was found to be $68.8 \%$ for $\mathrm{ZnO}$ NPs -treated animals and $41.6 \%$ for MTX-treated mice.

In a solid tumor, the average tumor volume in $[E]$ mice increased from $111.83 \pm 28.91 \mathrm{~mm}^{3}$ to $1655 \pm 5.3$ $\mathrm{mm}^{3}$ after 21 days. In MTX treated group the average tumor volume was observed to increase from $105.01 \pm 10.4 \mathrm{~mm}^{3}$ to $976 \pm 3.1 \mathrm{~mm}^{3}$. In ZnO NPs treated group the average tumor volume was observed to increase from $108.1 \pm 20.14 \mathrm{~mm}^{3}$ to $516 \pm 1.4 \mathrm{~mm}^{3}$, indicating the proliferation rate of tumor cells in treated mice was inhibited by $\mathrm{ZnO}$ NPs due to a decrease in tumor burden [Figure 1]. The body weight changes were significantly higher in ZnO NPs treated group significantly $(\mathrm{P}<0.0001)$ increased 1.7 fold more than the control indicating the effect of $\mathrm{ZnO}$ NPs in preventing tumor growth.

\subsection{Zn content analysis}

A significant $(P<0.0001)$ increase in the $\mathrm{Zn}$ content was found in the tumor of mice treated with $\mathrm{ZnO}$ nanoparticles $[\mathrm{E}+\mathrm{ZN}]$ as compared to the mammary gland of $\mathrm{ZnO}-\mathrm{NPs}$ control group [ZN] and other groups. In contrast, there was no significant difference in $\mathrm{Zn}$ content in the liver of treated groups $[\mathrm{ZN}]$ and $[\mathrm{E}+\mathrm{ZN}]$ and control mice. The liver showed a slight increase in the $\mathrm{Zn}$ content but it was not statistically significant [Figure 2].

\subsection{Effect of ZnO-NPs on DNA fragmentation}

DNA isolated from Ehrlich solid tumor in [E] group and liver tissue of $[\mathrm{E}+\mathrm{ZN}]$ group showed intact (non-degraded) bands near gel wells. In contrast, a variable degree of DNA fragmentation, revealed by DNA laddering and smearing, was noticed after the administration of ZnO-NPs or MTX. The most severe pattern of DNA fragmentation was observed in ESC mice treated with ZnO-NPs. liver tissue of $[\mathrm{E}+\mathrm{MTX}]$ group showed noticed DNA laddering [Figure 3].

\subsection{Oxidative stress markers}

\subsubsection{Effects of $\mathrm{ZnO}$-NPs upon Markers of Oxidative Stress in ESC tissue}

It has been suggested that oxidant generation and antioxidant depletion are the common pathways through which anticancer drugs trigger apoptosis in cancer cells. ${ }^{[37]}$ Therefore, the status of oxidants and antioxidants was examined in ESC treated with $\mathrm{ZnO}$ NPs or MTX. MDA levels were measured as markers of oxidants, whereas antioxidant status was examined by determining the SOD, CAT, and GSH. Results showed that the levels of SOD, CAT, and GSH were significantly decreased $(\mathrm{P}<0.01)$, MDA were increased $(\mathrm{P}<0.01)$ in tumor tissue of the ESC control group as compared to the mammary gland of the normal group. Figure (4) reveals that MTX induced toxicity; depletion in the levels of CAT, GSH, and SOD; $(\mathrm{P}<0.01)$, and a significant increase $(\mathrm{P}<0.01)$ in the level of MDA in tumor tissue were detected. Treatment of the Ehrlich solid tumor with $\mathrm{ZnO}$ NPs revealed the most significant decrease $(\mathrm{P}<$ 0.001) in the levels of CAT, GSH, and SOD and high significance $(\mathrm{P}<0.001)$ increase in the level of MDA in tumor tissue as compared with the Ehrlich solid tumor group [Figure 4].

\subsubsection{Effect of $\mathrm{ZnO}-\mathrm{NPs}$ on oxidative stress markers in liver tissue}

No significant changes in oxidative stress parameter found in liver tissues in the ZnO NPs group $[\mathrm{ZN}]$ when compared to a liver of the control group. And also between $[\mathrm{E}+\mathrm{ZN}]$ treated group when compared to $[\mathrm{ZN}]$ group. On the other hand, significant changes $(\mathrm{p}<0.01)$ in oxidative stress parameter found in liver tissues in the [E + MTX] group compared to the liver of the control group. ZnO-NPs administration at the dose of $10 \mathrm{mg} / \mathrm{kg}$ does not affect liver oxidative stress parameters [Figure 4]. 


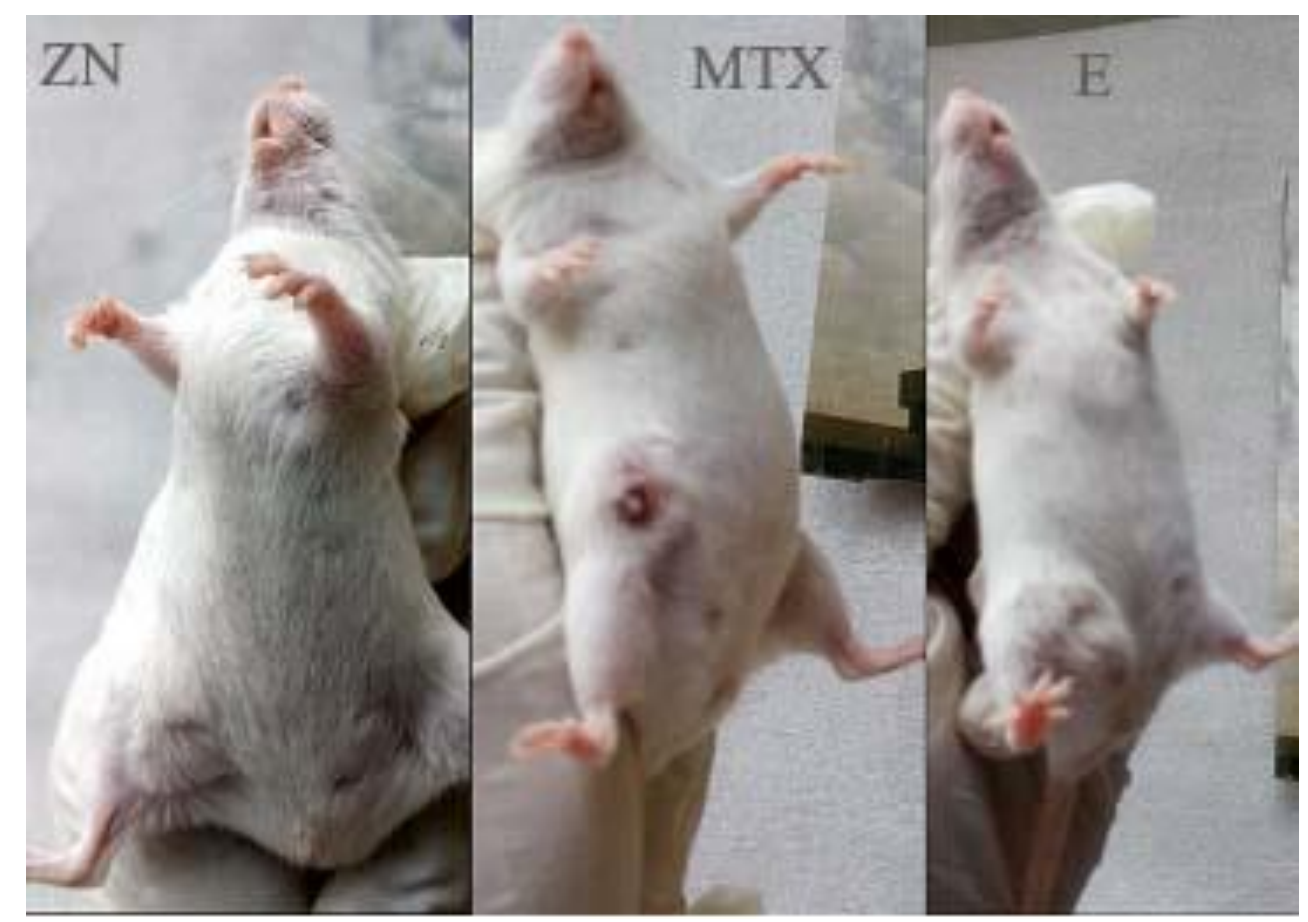

Figure 1: ZnO-NPs inhibits tumor growth in solid Ehrlich tumor. EAC cells were injected into Swiss albino mice $\left(2 \times 10^{6}\right.$ per mouse). After solid tumors grew to $\sim 100 \mathrm{~mm}^{3}$, the mice were i.p. treated with or without $\mathrm{ZnO}-$ NPs $(10 \mathrm{mg} / \mathrm{kg} /$ day $)$. Inhibited tumor growth as measured by tumor volume. Solid tumors in the ZnO-NPs treated mice were significantly smaller than those in the MTX-treated mice.

Table 1: effect of $\mathrm{ZnO}-\mathrm{NPs}$ on Bodyweight gain\% in ESC-bearing mice, Tumor weight, volume, tumor-growth inhibition rate (TIR\%), mean survival time (MST), and percent increase in life span (\% ILS).Data are presented as mean \pm SEM (ten animals /group) $* \mathrm{P}<0.05$, $* * \mathrm{P}<0.01$, and $* * * \mathrm{P}<0.001$ were set significant.

\begin{tabular}{|c|c|c|c|c|c|c|c|c|}
\hline & $\begin{array}{c}\text { Body } \\
\text { weight } \\
\text { gain \% }\end{array}$ & $\begin{array}{c}\text { Tumor } \\
\text { weight } \\
(\mathrm{g})\end{array}$ & $\begin{array}{c}\text { Tumor } \\
\text { volume } \\
\left(\mathrm{mm}^{3}\right)\end{array}$ & TIR\% & $\begin{array}{c}\text { Survival } \\
\text { time } \\
\text { range } \\
\text { (days) }\end{array}$ & $\begin{array}{c}\text { MST } \\
(\text { days })\end{array}$ & ILS\% & T/C\% \\
\hline E & -10.84 & $1.31 \pm 0.07$ & $1655 \pm 5.3$ & ----- & $31.25-40$ & 35.62 & $-\ldots----$ & ------ \\
\hline E+ZN & $37.11^{* * *}$ & $0.32 \pm 0.09^{* * *}$ & $516 \pm 1.4^{* * *}$ & $68.8^{* * *}$ & $65-86^{* * *}$ & $75.5^{* * *}$ & $111.66^{* * *}$ & $\begin{array}{c}211.66^{* *} \\
*\end{array}$ \\
\hline E+MTX & $-13.35^{*}$ & $0.89 \pm 0.11^{* *}$ & $976 \pm 3.1^{* *}$ & $41.6^{* *}$ & $45-65^{* *}$ & $55.6^{* *}$ & $55.3^{* *}$ & $156.52^{* *}$ \\
\hline
\end{tabular}




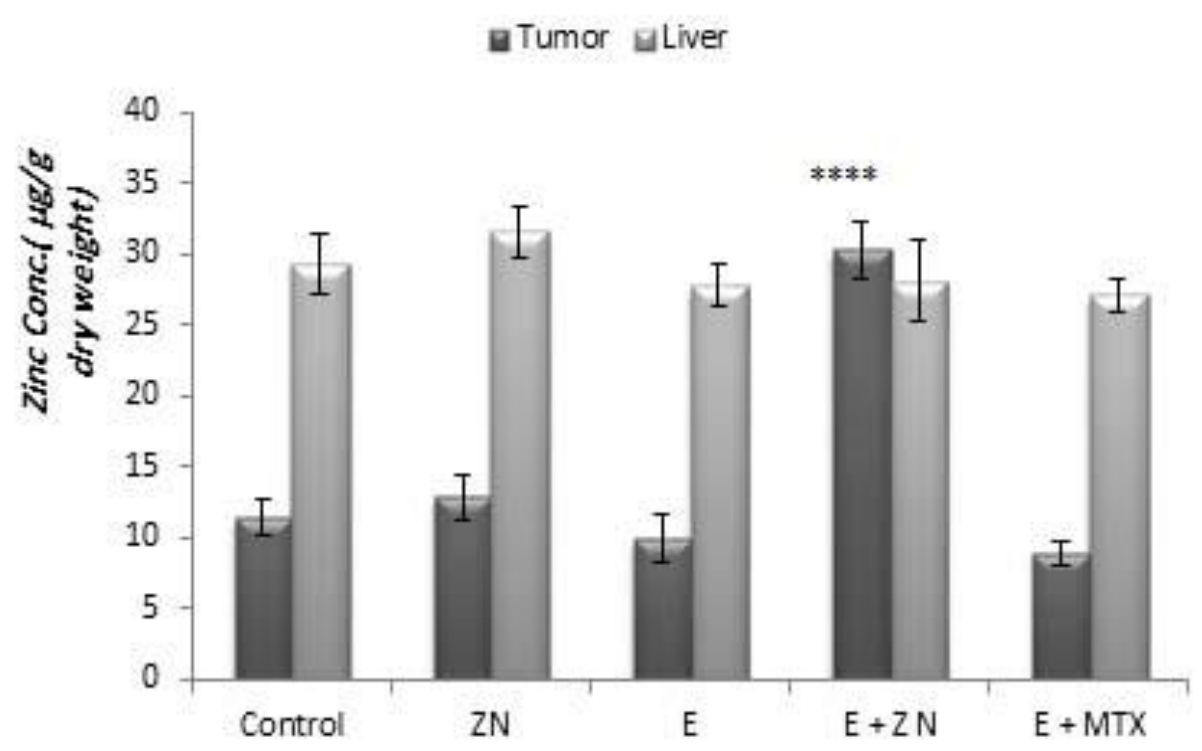

Figure 2: Zinc Concentration in tumor/mammary gland and liver in studied groups. Highly significant ${ }^{* * * *}(\mathrm{p}<0.0001)$ increase in tumor treated with $\mathrm{ZnO} \mathrm{NPs}[\mathrm{E}+\mathrm{ZN}]$.

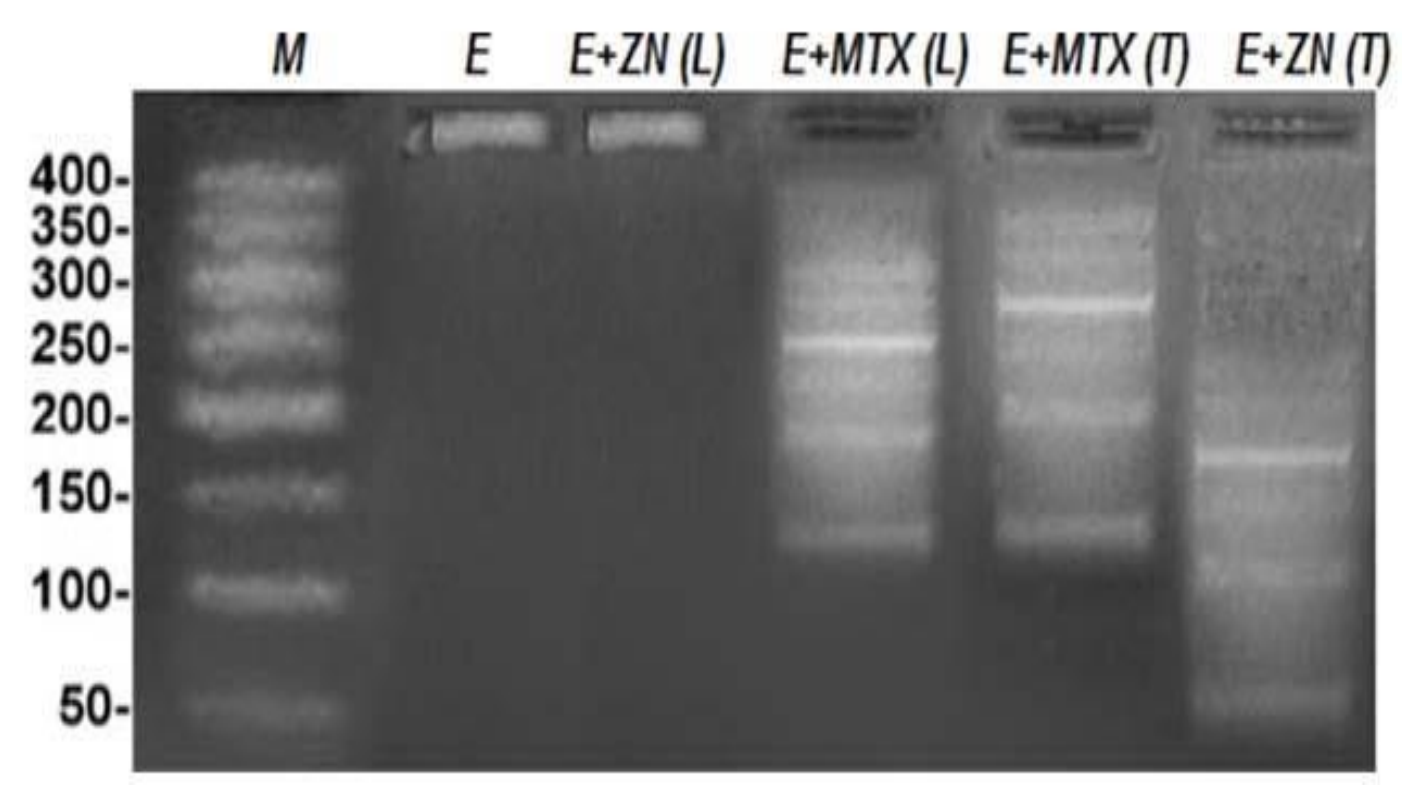

Figure 3: Ethidium bromide-stained agarose gel showing patterns of the extracted DNA. M is the marker lane 50 bp Ladder. Each lane has four pooled DNA samples from each group. E(T), Ehrlich group (tumor tissue); E+ ZN (L), Ehrlich group treated by ZnO-NPs (liver tissue); E + MTX(L), Ehrlich group treated by MTX (liver tissue); E + MTX(T), Ehrlich group treated by MTX (tumor tissue); E + ZN (T), Ehrlich group treated by ZnONPs (tumor tissue). The most severe pattern of DNA fragmentation was observed in ESC mice treated with ZnO-NPs. 

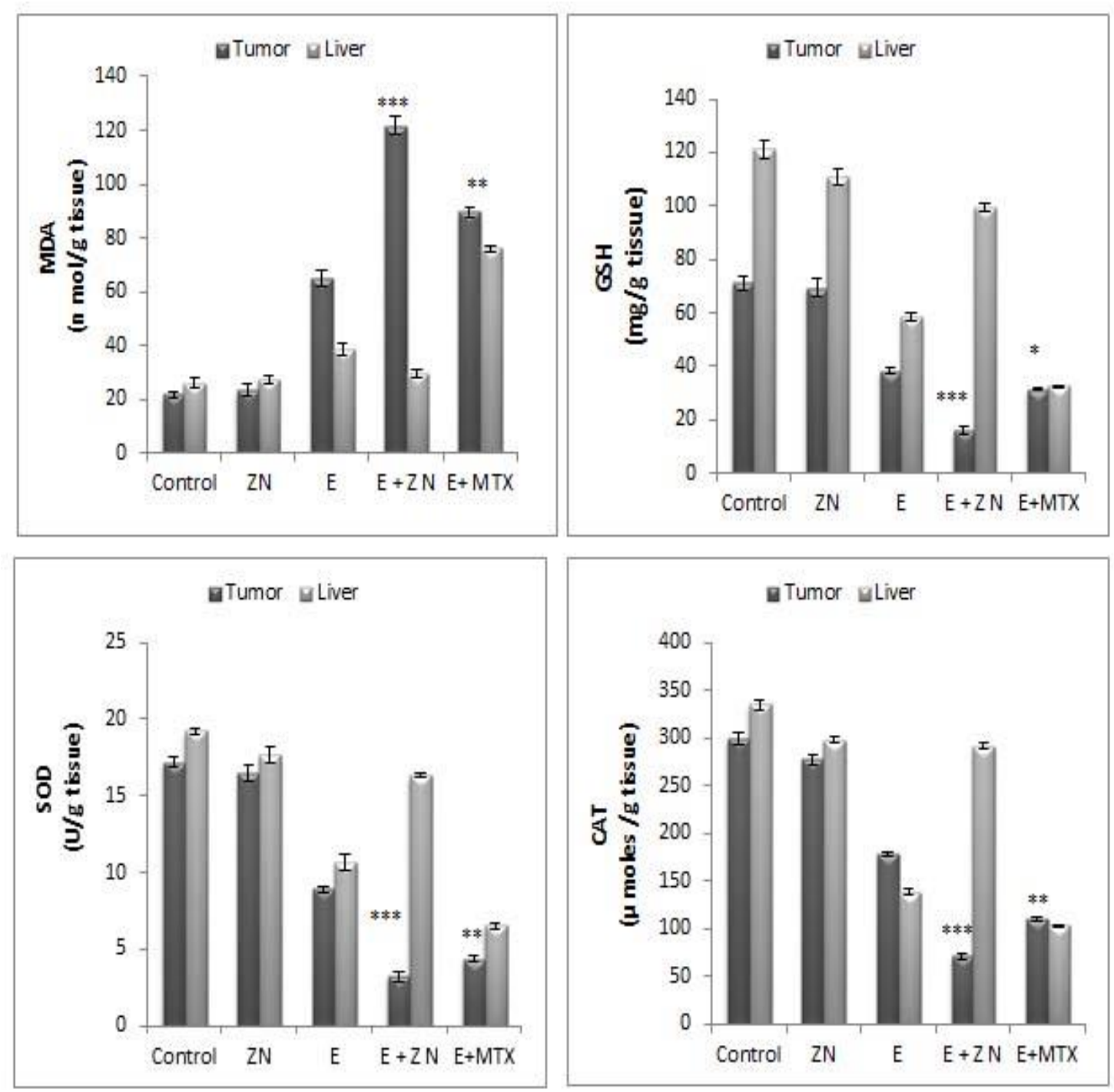

Figure 4: Effect of ZnO-NPs on oxidative stress biomarkers (malondialdehyde (MDA), reduced glutathione (GSH), catalase (CAT), and superoxide dismutase (SOD) activities in tumor/mammary gland and liver homogenates in studied groups. Data are the mean \pm SEM $* \mathrm{P}<0.05, * * \mathrm{P}<0.01$, and $* * * \mathrm{P}<0.001$ were set significant.

\section{Discussion}

Zinc oxide nanoparticles ( $\mathrm{ZnO}$ NPs) have received much attention for their implications in cancer therapy. ${ }^{[38]}$ Studies have shown that ZnO NPs induce cytotoxicity in a cell-specific and proliferation-dependent manner, with rapidly dividing cancer cells being the most susceptible, and quiescent cells being the least sensitive. ${ }^{[16,39]}$ The present study reveals the effects of ZnO NPs on Ehrlich solid tumor and normal tissues (mammary gland and liver) and provides significant insight into the possible selective mechanism through which $\mathrm{ZnO}$ NPs exert their toxic effects on these cells. Our results demonstrate the cytotoxic potential of ZnO NPs in the Ehrlich solid tumor. Oxidative stress was found to be the underlying mechanism behind $\mathrm{ZnO}$ NPs induced DNA damage and cell death.
In our study, we evaluate the cytotoxic activity of $\mathrm{ZnO}$ NPs on carcinoma and normal cells. The mice inoculated with Ehrlich carcinoma showed a significant decrease in body weight gain compared to the treated ones. This result agrees with those obtained by Badr El-Din et al. ${ }^{[40]}$ and Miranda-Vilela et al. ${ }^{[41]}$. Reduction in body weight resulted in stunted growth not only due to reduced food consumption but also due to the tumor burden with its massive growth rate. Bodyweight gain shows a significant increase in ESC treated with ZnO NPs which demonstrates antitumor activity against Ehrlich solid tumor, as evidenced by marked suppression of tumor volume, weight, growth inhibition rate; moreover, the tumors appeared to grow slowly and their morphology was discontinuous and fragmented. This indicates that $\mathrm{ZnO}$ NPs exerted some inhibitory effects upon the 
tumor cells. These findings may be attributed to reduced cell proliferation and/or increased apoptosis.

From another aspect, Zinc ( $\mathrm{Zn})$ distribution was measured in liver and Ehrlich tumor /mammary gland among groups. The mammary gland can resemble the normal control of Ehrlich solid, this type of Ehrlich tumor which appeared originally as a spontaneous breast carcinoma in a mouse can resemble breast cancer. ${ }^{[42]}$ There was a significant difference in the distribution of $\mathrm{Zn}$ among the studied groups. The highest concentration of $\mathrm{Zn}$ in tumor tissues was recorded, although the liver was found to be the target organ of $\mathrm{ZnO}$ NPs. ${ }^{[43]}$ High accumulation of zinc in tumor tissues proves that $\mathrm{ZnO}$ NPs were efficiently taken up by tumor tissues. ZnO NPs induce toxicity in a cell-specific and proliferation-dependent manner with rapidly dividing cells being the most susceptible and quiescent cells being the least sensitive. The marked difference in the cytotoxic response between cancer cells and their normal counterparts. ${ }^{[44]}$ Hanley et al ${ }^{[45]}$ observed that there is an inverse relationship between nanoparticle size and cytotoxicity in mammalian cells, as well as nanoparticle size and reactive oxygen species production. Additionally, targeting tumor tissues occurs through the extravasations of nanoparticles post-injection into the systemic blood circulation. The biodistribution of these particles is dependent on the characteristics of blood capillaries in the organs and tissues as well as the administration site, particle size and particle surface properties. ${ }^{[46]}$

Zinc oxide nanoparticles induced a notable DNA fragmentation in form of laddering. The present work recorded that the electrophoresis pattern of DNA isolated from the untreated Ehrlich tumor group displayed an absence of DNA fragments. On the other hand, the electrophoresis pattern of DNA isolated from ESC treated with $\mathrm{ZnO}$ NPs group displayed ladder-like DNA fragmentation which is characteristic of DNA damage. The disappearance of DNA fragment bands postulates loss of apoptosis evident by the tumor development. Some types of tumors are characterized by defects in apoptosis leading to immortal clones of cells. ${ }^{[4]}$ Most anticancer drugs have been known to cause DNA damage or suppress its replication, not necessarily killing the cells directly but inducing apoptosis. ${ }^{[48]}$ When resolved using agarose gel electrophoresis, these DNA fragments appear as a nucleosomal ladder, a widely recognized hallmark of apoptosis. One of the key possible modes thought to be responsible for the toxic effects exerted by $\mathrm{ZnO}$ NPs via oxidative stress is DNA damage. ${ }^{[49]}$ The generation of ROS has been attributed to their semiconductor and nanolevel characteristics which lead to ROS generation. ${ }^{[50-52]}$ The electrons and holes can react with the oxygen and hydroxyl ions, respectively, present in the aqueous environment of $\mathrm{ZnO}$ NPs. This produces highly reactive free radicals including the superoxide anion radical (from electrons) and the hydroxyl radical (from holes). ${ }^{[53]}$ Bai et al. ${ }^{[54]}$ showed a higher level of zinc concentration, which suggests that the level of ROS was high and the redox balance was impaired, eventually leading to DNA fragmentation in human ovarian cancer cells. Our findings indicated that the ZnO NP-treated group showed a higher level of zinc concentration in the tumor, which suggests that the level of ROS was high and the redox balance, was impaired, eventually leading to DNA fragmentation. Whereas ESC treated with ZnO NPs had started the apoptotic process, as was evident from DNA fragmentation analysis. Similarly, Akhtar et al. ${ }^{[5]}$ reported that $\mathrm{ZnO}$ NP-treated human liver cancer HepG2 cells showed remarkable fragmentation of DNA.

With elevated levels of oxidative stress, ZnO NPs show a deleterious effect on the lipid, protein, and nucleic acid of the tumor tissues. ${ }^{[56]}$ Elevated ROS can cause membrane damage through lipid peroxidation, protein denaturation, DNA damage, and cell death by apoptosis. ${ }^{[57]}$ It has been suggested that oxidant generation and antioxidant depletion are the common pathways through which anticancer drugs trigger apoptosis in cancer cells. ${ }^{[58]}$ Therefore, levels of MDA, GSH, along with the activities of antioxidant enzymes such as SOD and catalase in tumor and liver tissues were determined. The elevated level of MDA in ESC treated with ZnO NPs mice was observed in this study. The levels of the tri-peptide GSH and activity of antioxidant enzymes such as SOD and catalase were decreased after treatment with $\mathrm{ZnO}$ NPs. Depletion of GSH content for ZnO NPs was observed compared to controls suggesting that $\mathrm{ZnO}$ NPs is a potent ROS generator could be due to the increased generation of ROS and the excessive oxidative damage generated in mice. Xia et al. ${ }^{[59]}$ reported that $\mathrm{ZnO}$ NPs induce generation of reactive oxygen species which can lead to cell death in A375 cells. When the antioxidative capacity of the cell is exceeded. Glutathione, a ubiquitous and abundant antioxidant cellular tripeptide, was found to be strongly depleted after exposure to $\mathrm{ZnO}$ NPs. Superoxide dismutase is specialized to convert the highly toxic superoxide radical to less toxic $\mathrm{H}_{2} \mathrm{O}_{2}{ }^{[60]}$ The catalase enzyme reduces $\mathrm{H}_{2} \mathrm{O}_{2}$ to $\mathrm{H}_{2} \mathrm{O}^{[59]}$. More production of intracellular reactive oxygen species and more membrane lipid peroxidation in cells exposed to $\mathrm{ZnO}$ nanoparticles along with depletion of their antioxidant components suggest that oxidative stress might be a primary mechanism for the toxicity of $\mathrm{ZnO}$ NPs. These results agree with other studies which detected elevated levels of MDA in breast 
cancer. ${ }^{[61]}$ The findings here are consistent with those of Abd El-Aziz et al. ${ }^{[62]}$ who noted that Ehrlich tumors exhibited significant increases in MDA and considerable decreases in catalase and SOD. MDA content manifests the level of lipid peroxidation and indirectly represents the level of damage to the tissue.

The GSH redox system is important for attenuating oxidative stress and in this process, GSH as a generalist radical scavenger is converted to oxidized glutathione (GSSG), while glutathione reductase continuously converts GSSG back to GSH. ${ }^{63,64]}$ The malignant cells of different cancer types exhibit heterogeneity in the levels of oxidative stress associated with various expressive levels of SOD and other antioxidant enzymes. ${ }^{[65]}$ Decreased SOD activity in tumor tissues after treatment with $\mathrm{ZnO}$ NPs may be due to the increase in lipid peroxide. This can result in the accumulation of superoxide anions, a highly diffusible and potent oxidizing radical capable of traversing membranes causing deleterious effects. ${ }^{[66]}$ Throughout this experiment, the administration of ZnO NPs enhanced cytotoxicity by the generation of reactive oxygen species (ROS), leading to oxidative stress and eventually cell death.

\section{CONCLUSION}

By these studies, it was confirmed that $\mathrm{ZnO}$ NPs are safe and effective candidates to reduce the growth of cancer cells with no effect on normal cells according to nanoparticle size and concentration. Therefore, it is expected that $\mathrm{ZnO}$ NPs may be regarded as a new class of antitumorigenic and anticarcinogenic agents but we need more investigations and field applications.

\section{References}

1. Smalley K, Herlyn M. Towards the targeted therapy of melanoma. Mini reviews in medicinal chemistry 2006;6: 387-393.

2. Aldubayan MA, Elgharabawy RM, Ahmed AS, Tousson E. Antineoplastic Activity and Curative Role of Avenanthramides against the Growth of Ehrlich Solid Tumors in Mice. Oxidative Medicine and Cellular Longevity 2019;2019.

3. Tousson E, Hafez E, Masoud A, Hassan AA. Abrogation by curcumin on testicular toxicity induced by cisplatin in rats. J Cancer Res Treat 2014;2: 64-68.

4. Tousson E, Hafez E, Zaki S, Gad A. The cardioprotective effects of L-carnitine on rat cardiac injury, apoptosis, and oxidative stress caused by amethopterin. Environmental Science and Pollution Research 2016;23: 20600-20608.

5. Tousson E, Bayomy MF, Ahmed AA. Rosemary extract modulates fertility potential, DNA fragmentation, injury, KI67 and P53 alterations induced by etoposide in rat testes. Biomedicine \& Pharmacotherapy 2018;98: 769-774.

6. Al-Rasheed NM, El-Masry TA, Tousson E, Hassan HM, Al-Ghadeer A. Hepatic protective effect of grape seed proanthocyanidin extract against Gleevecinduced apoptosis, liver Injury and Ki67 alterations in rats. Brazilian Journal of Pharmaceutical Sciences 2018;54.

7. Al-Rasheed NM, El-Masry TA, Tousson E, Hassan HM, Al-Ghadeer A. Protective Potential of Grape Seed Proanthocyandins Extract against Glivec (Imatinib Mesylate) Induced Liver Toxicity and Oxidative Stress in Male Rats. Annual Research \& Review in Biology 2017; 20: 1-9.

8. Bosanquet AG, Bell PB. Ex vivo therapeutic index by drug sensitivity assay using fresh human normal and tumor cells. Journal of experimental therapeutics \& oncology 2004;4.

9. Pandurangan M, Kim DH. In vitro toxicity of zinc oxide nanoparticles: a review. Journal of Nanoparticle Research 2015;17: 158.

10.Wang ZL. Splendid one-dimensional nanostructures of zinc oxide: a new nanomaterial family for nanotechnology. ACS nano 2008;2: 1987-1992.

11.Padmavathy N, Vijayaraghavan R. Enhanced bioactivity of $\mathrm{ZnO}$ nanoparticles - an antimicrobial study. Science and technology of advanced materials 2008;9: 035004.

12.Becheri A, Dürr M, Nostro PL, Baglioni P. Synthesis and characterization of zinc oxide nanoparticles: application to textiles as UVabsorbers. Journal of Nanoparticle Research 2008;10: 679-689. 
13.Snyder-Talkington BN, Qian Y, Castranova $\mathrm{V}$, Guo NL. New perspectives for in vitro risk assessment of multiwalled carbon nanotubes: application of coculture and bioinformatics. Journal of Toxicology and Environmental Health, Part B 2012;15: 468-492.

14.Chandrasekaran M, Pandurangan M. In vitro selective anti-proliferative effect of zinc oxide nanoparticles against co-cultured $\mathrm{C} 2 \mathrm{C} 12$ myoblastoma cancer and 3T3-L1 normal cells. Biological trace element research 2016;172: 148-154.

15.Rasmussen JW, Martinez E, Louka P, Wingett DG. Zinc oxide nanoparticles for selective destruction of tumor cells and potential for drug delivery applications. Expert opinion on drug delivery 2010;7: 1063-1077.

16.Hanley C, Layne J, Punnoose A, Reddy K, Coombs I, Coombs A, Feris K, Wingett D. Preferential killing of cancer cells and activated human $\mathrm{T}$ cells using $\mathrm{ZnO}$ nanoparticles. Nanotechnology 2008;19: 295103.

17.Wang X, Wang W, Li L, Perry G, Lee H-g, Zhu X. Oxidative stress and mitochondrial dysfunction in Alzheimer's disease. Biochimica et Biophysica Acta (BBA)Molecular Basis of Disease 2014;1842: 12401247.

18.Saggu S, Sakeran MI, Zidan N, Tousson E, Mohan A, Rehman H. Ameliorating effect of chicory (Chichorium intybus L.) fruit extract against 4-tert-octylphenol induced liver injury and oxidative stress in male rats. Food and chemical toxicology 2014;72: 138-146.

19.El-Demerdash FM, Tousson EM, Kurzepa J, Habib SL. Xenobiotics, Oxidative Stress, and Antioxidants. Oxidative Medicine and Cellular Longevity 2018; Article ID 9758951, 2

https://doi.org/10.1155/2018/9758951 pages.

20.Basuony M, Hafez E, Tousson E, Massoud A, Elsomkhraty S, Eldakamawy S. Beneficial role of Panax ginseng root aqueous extract against Cisplatin induced blood toxicity in rats. Am J Biol Chem 2015;3: 1-7.
21.El-Masry TA, Al-Shaalan NH, Tousson E, ElMorshedy K, Al-Ghadeer A. P53 expression in response to equigan induced testicular injury and oxidative stress in male rat and the possible prophylactic effect of star anise extracts. Annual Research \& Review in Biology 2018;14: 1-8.

22.Elmasry TA, Al-Shaalan NH, Tousson E, ElMorshedy K, Al-Ghadeer A. Star anise extracts modulation of reproductive parameters, fertility potential and DNA fragmentation induced by growth promoter Equigan in rat testes. Brazilian Journal of Pharmaceutical Sciences 2018;54:e17261; http://dx.doi.org/10.1590/s2175$\underline{9790201800011726154 .}$

23.Shao G, Lai W, Wan X, Xue J, Wei Y, Jin J, Zhang L, Lin Q, Shao Q, Zou S. Inactivation of EGFR/AKT signaling enhances TSAinduced ovarian cancer cell differentiation. Oncology reports 2017;37: 2891-2896.

24.Oyouni AAA, Saggu S, Tousson E, Rehman H. Immunosuppressant drug tacrolimus induced mitochondrial nephrotoxicity, modified PCNA and Bcl-2 expression attenuated by Ocimum basilicum L. in CD1 mice. Toxicology reports 2018;5: 687-694.

25.Elkeiy MM, Khamis AA, El-Gamal MM, Gazia MMA, Zalat ZA, El-Magd MA. Chitosan nanoparticles from Artemia salina inhibit progression of hepatocellular carcinoma in vitro and in vivo. Environmental Science and Pollution Research 2018;1-13.

26.El Fatoh MFA, Farag MR, Shafika A, Hussein MA, Kamel M, Salem G. Cytotoxic Impact of Zinc Oxide Nanoparticles against Ehrlich Ascites Carcinoma Cells in Mice. Int. J. Pharma Sci 2014;4: 560-564.

27.Malik F, Kumar A, Bhushan S, Mondhe DM, Pal HC, Sharma R, Khajuria A, Singh S, Singh G, Saxena AK. Immune modulation and apoptosis induction: Two sides of antitumoural activity of a standardised herbal formulation of Withania somnifera. European Journal of Cancer 2009;45: 1494-1509. 
28.Chastre J, Viau F, Brun P, Pierre J, Dauge MC, Bouchama A, Akesbi A, Gibert C. Prospective evaluation of the protected specimen brush for the diagnosis of pulmonary infections in ventilated patients. American Review of Respiratory Disease 1984;130: 924-929.

29.Salem ML, Shoukry NM, Teleb WK, AbdelDaim MM, Abdel-Rahman MA. In vitro and in vivo antitumor effects of the Egyptian scorpion Androctonus amoreuxi venom in an Ehrlich ascites tumor model. SpringerPlus 2016;5: 570.

30.Plowman J, Dykes DJ, Hollingshead M, Simpson-Herren L, and Alley MC. Human tumor xenograft models in NCI drug development. Anticancer Drug Development Guide 1997;101-125.

31.Moss JC, Hardaway CJ, Richert JC, Sneddon J. Determination of cadmium copper, iron, nickel, lead and zinc in crawfish [Procambrus clarkii] by inductively coupled plasma optical emission spectrometry: a study over the 2009 season in Southwest Louisiana. Microchemical Journal 2010;95: 5-10.

32.Abd Eldaim MA, Tousson E, El Sayed IET, Awd WM. Ameliorative effects of Saussurea lappa root aqueous extract against Ethephoninduced reproductive toxicity in male rats. Environmental toxicology 2019;34: 150-159.

33.El Atrash A, Dawood L, Tousson E, Salama A. Neuroprotective role of vitamin B3 in experimentally induced oxidative stress. Int. J. Clin. Exp. Neurol 2015;3: 21-25.

34.Salama AF, Tousson E, Shalaby KA, Hussien HT. Protective effect of curcumin on chloroform as by-product of water chlorination induced cardiotoxicity. Biomedicine \& Preventive Nutrition 2014;4: 225-230.

35.Habig WH, Pabst MJ, Jakoby WB. Glutathione S-transferases the first enzymatic step in mercapturic acid formation. Journal of biological Chemistry 1974;249: 7130-7139.

36.Barakat LA, Tousson E, Ibrahim W, ElHakeem AA. Role of propolis in improving hepatic and renal damage in boldenone undecylenate in male rats. American Journal of Biological Chemistry 2015;3: 8.

37.Yip N, Fombon I, Liu P, Brown S, Kannappan V, Armesilla A, Xu B, Cassidy J, Darling J, Wang W. Disulfiram modulated ROS-MAPK and $\mathrm{NF \kappa B}$ pathways and targeted breast cancer cells with cancer stem cell-like properties. British journal of cancer 2011;104: 1564.

38.Zhang H, Chen B, Jiang H, Wang C, Wang H, Wang $\mathrm{X}$. A strategy for $\mathrm{ZnO}$ nanorod mediated multi-mode cancer treatment. Biomaterials 2011;32: 1906-1914.

39.Premanathan M, Karthikeyan K, Jeyasubramanian K, Manivannan G. Selective toxicity of $\mathrm{ZnO}$ nanoparticles toward Grampositive bacteria and cancer cells by apoptosis through lipid peroxidation. Nanomedicine: Nanotechnology, Biology and Medicine 2011;7: 184-192.

40.Badr El-Din NK, Noaman E, Ghoneum M. In vivo tumor inhibitory effects of nutritional rice bran supplement MGN-3/Biobran on Ehrlich carcinoma-bearing mice. Nutrition and cancer 2008;60: 235-244.

41.Miranda-Vilela AL, Portilho FA, de Araujo VG, Estevanato LL, Mezzomo BP, Maria de Fátima M, and Lacava ZG. The protective effects of nutritional antioxidant therapy on Ehrlich solid tumor-bearing mice depend on the type of antioxidant therapy chosen: histology, genotoxicity and hematology evaluations. The Journal of nutritional biochemistry 2011;22: 1091-1098.

42.Ferreira M, Barcelos L, Teixeira M, Bakhle Y, Andrade S. Tumor growth, angiogenesis and inflammation in mice lacking receptors for platelet activating factor (PAF). Life sciences 2007;81: 210-217.

43. Sharma V, Singh P, Pandey AK, Dhawan A. Induction of oxidative stress, DNA damage and apoptosis in mouse liver after sub-acute oral exposure to zinc oxide nanoparticles. Mutation Research/Genetic Toxicology and Environmental Mutagenesis 2012;745: 84-91. 
44.Punnoose A, Kongara MR, Wingett D. Preferential killing of cancer cells and activated human $\mathrm{T}$ cells using $\mathrm{ZnO}$ nanoparticles. United States Patent 2012; US 8,187,638 B2.

45.Hanley C, Thurber A, Hanna C, Punnoose A, Zhang J, Wingett DG. The influences of cell type and $\mathrm{ZnO}$ nanoparticle size on immune cell cytotoxicity and cytokine induction. Nanoscale research letters 2009;4: 1409.

46.Perry JL, Reuter KG, Luft JC, Pecot CV, Zamboni W, DeSimone JM. Mediating passive tumor accumulation through particle size, tumor type, and location. Nano letters 2017;17: 2879-2886.

47.Rashid S. Hallmarks of Cancer Cell. Cancer and Chemoprevention: An Overview. Springer, Singapore 2017; 3-13.

48.Dai H, Ge S, Guo J, Chen S, Huang M, Yang J, Sun S, Ling Y, Shi Y. Development of novel bis-pyrazole derivatives as antitumor agents with potent apoptosis induction effects and DNA damage. European journal of medicinal chemistry 2018;143: 1066-1076.

49.Ng CT, Yong LQ, Hande MP, Ong CN, Yu LE, Bay BH, Baeg GH. Zinc oxide nanoparticles exhibit cytotoxicity and genotoxicity through oxidative stress responses in human lung fibroblasts and Drosophila melanogaster. International journal of nanomedicine 2017;12: 1621.

50.Bhat SS, Qurashi A, Khanday FA. ZnO nanostructures based biosensors for cancer and infectious disease applications: perspectives, prospects and promises. TrAC Trends in Analytical Chemistry 2017;86: 113.

51.Tousson E, Hegazy M, Hafez E, Ahmed E. The effect of L-carnitine on amethopterininduced toxicity in rat large intestine. J Cancer Res Treat 2014;2: 55-63.

52.Tousson E, Ibrahim W, Barakat L, Abd ElHakeem A. Role of Proplis administration in boldenone-induced oxidative stress, Ki-67 protein alterations and toxicity in rat liver and kidney. Int J Sci Eng Res 2015;6: 660-664.
53.Malhotra SPK, Mandal T. Biomedical applications of Zinc Oxide nanomaterials in cancer treatment: a review. SCIREA J Chem 2016;1: 67-89.

54.Bai D-P, Zhang X-F, Zhang G-L, Huang Y-F, Gurunathan S. Zinc oxide nanoparticles induce apoptosis and autophagy in human ovarian cancer cells. International journal of nanomedicine 2017;12: 6521.

55.Akhtar MJ, Ahamed M, Kumar S, Khan MM, Ahmad J, Alrokayan SA. Zinc oxide nanoparticles selectively induce apoptosis in human cancer cells through reactive oxygen species. International journal of nanomedicine 2012;7: 845 .

56.Hoseinzadeh E, Makhdoumi P, Taha P, Hossini H, Stelling J, Amjad Kamal M. A review on nano-antimicrobials: Metal nanoparticles, methods and mechanisms. Current drug metabolism 2017;18: 120-128.

57.Ding X, Yu L, Ge C, Ma H. Protective effect of DHEA on hydrogen peroxide-induced oxidative damage and apoptosis in primary rat Leydig cells. Oncotarget 2017;8: 16158.

58.Kawahara B, Moller T, Hu-Moore K, Carrington S, Faull KF, Sen S, Mascharak PK. Attenuation of Antioxidant Capacity in Human Breast Cancer Cells by Carbon Monoxide through Inhibition of Cystathionine $\beta$-Synthase Activity: Implications in Chemotherapeutic Drug Sensitivity. Journal of medicinal chemistry 2017;60: 8000-8010.

59.Xia T, Kovochich M, Brant J, Hotze M, Sempf J, Oberley T, Sioutas C, Yeh JI, Wiesner MR, Nel AE. Comparison of the abilities of ambient and manufactured nanoparticles to induce cellular toxicity according to an oxidative stress paradigm. Nano letters 2006;6: 1794-1807.

60.Raafat BM, El-Barbary A, Touson E, Aziz S. Di-Mercapto Succinic Acid (DMSA) and vitamin $C$ chelating potency in lead intoxication, regarding oxidative stress and apoptotic related proteins in rabbits. Journal of Genetic Engineering and Biotechnology 2011;9: 121-131. 
61.Kalaiselvi P, Pragasam V, Chinnikrishnan S, Veena CK, Sundarapandiyan R, Varalakshmi P. Counteracting adriamycin-induced oxidative stress by administration of $\mathrm{N}$-acetyl cysteine and vitamin E. Clinical Chemistry and Laboratory Medicine (CCLM) 2005;43: 834-840.

62.El-Aziz AA, Hefni M, Shalaby AM. International Journal of Current Research and Academic Review. Int. J. Curr. Res. Aca. Rev 2014;2: 330-357.

63.Pearson-Smith JN, Liang LP, Rowley SD, Day BJ, Patel M. Oxidative stress contributes to status epilepticus associated mortality. Neurochemical research 2017; 42: 2024-2032.

64.Castro L, Kviecinski M, Ourique F, Parisotto E, Grinevicius V, Correia J, Wilhelm Filho D, Pedrosa R. Albendazole as a promising molecule for tumor control. Redox biology 2016;10: 90-99.

65.Miar A, Hevia D, Muñoz-Cimadevilla H, Astudillo A, Velasco J, Sainz RM, Mayo JC. Manganese superoxide dismutase (SOD2/MnSOD)/catalase and SOD2/GPx1 ratios as biomarkers for tumor progression and metastasis in prostate, colon, and lung cancer. Free Radical Biology and Medicine 2015;85: 45-55.

66.Che M, Wang R, Li X, Wang H-Y, Zheng XS. Expanding roles of superoxide dismutases in cell regulation and cancer. Drug discovery today 2016;21: 143-149. 